\title{
Floral maturation and changing air temperatures influence scent volatiles biosynthesis and emission in Jasminum auriculatum Vahl.
}

\author{
Monica Barman ${ }^{1}$ and Adinpunya Mitra ${ }^{1}$ \\ ${ }^{1}$ Indian Institute of Technology Kharagpur
}

June 25, 2020

\begin{abstract}
Benzenoid and terpenoid volatiles are the major compounds contributing to the unique floral scent of Jasminum auriculatum. Biosynthesis and emission of specialized scent metabolites showed maturation stage specific pattern; maximum scent emission was observed when flowers start unfurling and become fully opened under in situ condition. The activities of volatile biosynthesizing enzymes and expressions of several scent-related genes correlated well with the fragrance emission patterns. We also assessed the impact of varying air temperatures $\left(20^{\circ} \mathrm{C}, 25^{\circ} \mathrm{C}, 30^{\circ} \mathrm{C}\right.$ and $\left.35^{\circ} \mathrm{C}\right)$ on the metabolism as well as vaporization of scent volatiles. The contents of both emitted and endogenous volatiles were higher at either $25^{\circ} \mathrm{C}$ or $30^{\circ} \mathrm{C}$ and showed relatively lower amounts at both border-range temperatures $\left(20^{\circ} \mathrm{C}\right.$ and $\left.35^{\circ} \mathrm{C}\right)$. Further, the activities of key pathway enzymes and expressions of several scent-related genes under varying temperatures exhibited similar trends with the scent emission patterns. Analysis of non-volatile metabolite contents from flowers grown under different air temperatures suggests a perturbation occurring in the primary metabolism and immediate precursors of scent compounds. The knowledge base created through these studies shall be helpful in improving the yield of floral scent production from such horticulturally important plants in controlled cultivation systems.
\end{abstract}

\section{INTRODUCTION}

Jasmines are one of the oldest propagated flowering species cultivated mainly because of their unique sweet fragrance note. These horticulturally important flowers have many commercial applications in perfumery and natural cosmetic product formulation. Jasmines are utilized for producing floral wax, flavoured tea and essential oils (Ito et al., 2002; Edris et al., 2008). Around 200 species of Jasminumare known to be distributed throughout the tropical and sub-tropical regions of the globe. Many of the intensely scented species such as, Jasminum sambac, J. grandiflorum, J. auriculatumand J. ajonicum are cultivated extensively in many Eurasian countries primarily for producing attars and other perfumery products (Gupta and Chandra, 1957). Another jasmine species namely, J. auriculatum is also propagated at commercial scale since ages for its fragrant white flowers with maximum floral flush in the summer. This species is native to India producing scented flowers with entirely different olfactory scent note utilized widely in manufacturing concretes and absolutes (Joulain and Laurent., 1995) and also exploited in producing jasmine tea (Ito et al., 2002).

Floral fragrance comprises of an amalgamation of many micro chemicals which are highly volatile in nature. These specialized metabolites are mostly non-polar, have low boiling point and have high vapor pressure. These powerful molecules are produced by the plants mainly to deter herbivores, acts as repellents and helps in pollination. Volatile molecules may not always be released from the floral tissue immediately after biosynthesis. These compounds are often retained in floral tissue in soluble phase and are emitted as scent upon vaporization (Oyama-Okubo et al., 2005). Several floral volatile compounds are stored in vacuoles as water soluble glycosides (Watanabe et al., 1993; Barman and Mitra, 2019), upon physiological necessity, these compounds are cleaved by hydrolytic enzymes and subsequently released as fragrant molecules from floral tissue (Reuveni et al., 1999). In the past decades, a range of scent compounds were identified in many scented 
flowers such as,Rosa, (Helsper et al., 1998; Hendel-Rahmanim et al., 2007),Petunia (Schuurink et al., 2006), Antirrhinum (Kolosoba et al., 2001), Matricaria (Irmisch et al., 2012), Clarkia(Raguso and Pichersky, 1995), Murraya (Paul et al., 2019). Further, essential oils extracted from various scented flowers were reported to possess many pharmacological values (Kuroda et al., 2005; Wei and Shibamoto., 2007).

Floral scent compounds are broadly categorized into three major classes depending upon their biosynthetic routes viz. fatty acid derivatives, phenylpropanoids/benzenoids and terpenoids compounds (Pickersky et al., 2006). Volatiles metabolism at molecular levels in many scented flowers was studied throughout floral lifespan (Pichersky et al., 1994; Hendel-Rahmanim et al., 2007; Muhlemann et al., 2014). These include expression analysis of linalool synthesis in Clarkia breweri(Pichersky et al., 1994), J. grandiflorum (Pragadheesh et al., 2017), acetyl-CoA-benzylalcohol acetyltransferase (BEAT) in C. breweri (Dudareva et al., 1998), alcohol acetyl tranferases (AAT) inRosa hybrida (Shalit et al., 2003). In addition, transcription factors belonging to MYB R2R3 superfamily were also studied in connection with the upregulation of genes for benzenoid volatiles formation (Schuurink et al., 2006; Liu et al., 2015).

The fragrance emission from flowers is regulated by both metabolic and vaporization processes (Sagae et al., 2008). The biosynthesis and emission of floral fragrance are modulated not only by the floral developmental stages of maturity and circadian rhythm but also by other environmental factors such as light and temperature (Dudareva et al., 2013; Cheng et al., 2016). Among the environmental factors, air temperature was known to play a major role in the biosynthesis and emission of floral fragrance (Cheng et al., 2016; Hu et al., 2013). Earlier work on scented flowers (such as Osmanthus fragrans andPetunia hybrida) reported variations in the composition of scent volatiles with gradual increase in air temperature (Fu et al., 2017; Sagae et al., 2008). In Lilium sp. the amount of release of floral volatiles was found to be highest at $30^{\circ} \mathrm{C}$ while least emission recorded at $10^{\circ} \mathrm{C}$ in the lower range and $40{ }^{\circ} \mathrm{C}$ at the upper range (Hu et al., 2013). In Trifolium repens, higher content of emitted floral volatiles was reported when plants are grown at $20^{\circ} \mathrm{C}$ (Jakobsen and Olsen, 1994). Phenylalanine ammonia-lyase (PAL), the entry point enzyme of phenylpropanoid/benzenoid pathway is known to influence the synthesis of phenylpropanoid/benzenoid floral volatiles. PAL activity can be negatively affected by increase in the atmospheric temperature (Shaked-Sachray et al., 2002; Cna'ani et al., 2015). The transcript accumulation of certain upstream and downstream structural genes involved in the phenylpropanoid/benzenoid scent production inPetunia flowers are also affected by variations in air temperature conditions (Cna'ani et al., 2015). Terpene emission was also known to be primarily influenced by temperature and humidity. The monoterpene emission is also dependent on the surface area of oil which primarily indicates the presence of volatiles as liquid endogenous form within the plant tissue (Dement et al., 1975).

Previous studies on flowers of Jasminum species mainly focused on the scent volatiles composition (Bera et al., 2015; Barman and Mitra, 2019). Earlier research from the authors' laboratory has provided some relevant information related to the enzymes involved in floral scent production in J. sambac (Bera et al., 2017), one of the most commercially utilized Jasminum species. Subsequently we have also proposed a hypothesis that most of the floral scent compounds inJasminum spp. are biosynthesis and stored in the form of either glycosylated or free endogenous volatile compounds, and these volatiles are emitted following a certain rhythmic pattern (Barman and Mitra, 2019). No information, however, is available on the biosynthetic pathway involving the role of structural genes and enzymes responsible for scent production in other scented Jasminum species. While $J$. sambac is grown in many tropical and subtropical countries, J. auriculatum cultivation is mostly restricted in Indian subcontinent during summer months. It is therefore important to assess the role of temperature in the biosynthesis of floral volatiles in $J$. auriculatum more specifically to understand if fluctuations in the air temperature affect the scent volatiles accumulation in this species. Outcome of such study can pave new ways for cultivation of $J$. auriculatum in climate resilient areas of the tropics. Since jasmines grow mainly in countries under tropical climate, an understanding on the role of air temperature during blooming phase for maximum accumulation of scent volatiles shall be beneficial to farmers and floriculture traders.

In this manuscript, we first studied the physiology of scent volatiles synthesis and emission in J. auriculatum 
at different stages of floral maturation throughout lifespan under in situ condition. Upon identification of the appropriate flower maturation stage where maximum scent emission occurred, we then studied at that time point under controlled conditions the influence of a range of air temperatures in modulating scent volatiles synthesis and emission reflecting the climate of tropics. More specifically, we measured the amount of active enzymes (in terms of their in vitroactivities) of phenylalanine ammonia-lyase (PAL), phenylacetaldehyde reductase (PAR), acetyl-CoA-benzylalcohol acetyltransferase (BEAT), monoterpene synthase (MTS) and $\beta$-glucosidase involved in the biosynthesis of benzenoid and monoterpenoid volatiles in J. auriculatum grown in situand also at different air temperature regime. The expression levels of the structural genes and transcription factor involved in the biosynthesis of benzenoid and terpenoid volatiles were also studied to draw a correlation between the scent related gene expression and volatile emission patterns. Finally, the concentrations of non-volatile metabolites were also assessed from mature buds to understand the role of air temperature in modulating the upstream precursors of scent compounds.

\section{MATERIALS AND METHODS}

\subsection{Plant material and growth conditions}

$J$. auriculatum plants were cultivated in the experimental field of the department at Indian Institute of Technology Kharagpur, India. All the experiments were carried out in the summer of 2018 and 2019 subsequently. The flowering occurs from May and lasts till August. The average lowest and highest temperatures of the region during May-June ranged between $24 \pm 3^{\circ} \mathrm{C}$ to $36 \pm 3^{\circ} \mathrm{C}$ respectively and the average relative humidity during this period was around $78 \%$, respectively. The in situ experiments were carried on flowers of field-grown plants under natural day-light conditions from six different floral maturation stages namely, early bud: Stage 1 (S1), mid-bud: Stage 2 (S2), late bud: Stage 3 (S3), flower blooming: Stage 4 (S4), fully bloomed flower: Stage 5 (S5) and senescing flower: Stage 6 (S6). Flowers of S1 was observed one day prior to flower blooming; S2 was observed at morning on the day of flower blooming; S3 was in the afternoon on the day of flower blooming; S4 was in the evening at the time of flower blooming; S5 was in the night on the day of flower blooming; S6 was observed the next morning of flower blooming.

For controlled-temperature related studies, the plants were acclimatized for five days at particular air temperature in a growth chamber (LabTech India Pvt. Ltd.). The plants were incubated under four different temperature conditions $20^{\circ} \mathrm{C}, 25^{\circ} \mathrm{C}, 30^{\circ} \mathrm{C}$ and $35^{\circ} \mathrm{C}$ respectively, where relative humidity of $70 \%$, light intensity of 2000 lux (maintained via cool white fluorescent lamps) and $12 \mathrm{~h} / 12 \mathrm{~h}(06.00 \mathrm{~h}-18.00 \mathrm{~h} / 18.00 \mathrm{~h}$ $06.00 \mathrm{~h}$ ) light/dark cycle was maintained.

\subsection{Headspace collection of emitted floral volatiles}

Collection of emitted volatiles from in situ and different temperature grown flowers was done from live intact flowers with the use of glass bulb by the method as described by Barman et al. (2020) where headspace collected volatiles were trapped in $30 \mathrm{mg}$ of Porapak ${ }^{\circledR}$ Q 80/100 mesh (Supelco) adsorbent matrix and the scent molecules were eluted out from the matrix by using $150 \mu \mathrm{l}$ of dichloromethane (DCM) for further injection and analysis in GC-MS system.

\subsection{Preparation and collection of free and glycosyl-linked endogenous scent compounds}

The free and de-glycosylated endogenous volatiles were collected from the flowers grown under different temperature conditions upon using the method as described earlier by Barman and Mitra (2019). After extracting the emitted volatiles, flowers were plucked from the plants and frozen immediately in liquid nitrogen to get the free endogenous volatiles. The volatiles were collected by powdering the harvested flowers and extracting in DCM solvent. The glycosyl-linked endogenous volatiles were collected from petal residues of mature buds grown under different temperature. Hydrolysis of bound glycosyl moiety from volatile compounds was carried out with the help of $200 \mu \mathrm{l}$ of viscozyme ${ }^{\circledR} \mathrm{L}$ (Sigma-Aldrich). The de-glycosylated volatiles were extracted in DCM. The water molecules from the extract were removed by using anhydrous sodium sulphate.

\subsection{Analysis and quantification of volatile compounds by GC-MS system}


The analysis of emitted, free endogenous and bound endogenous volatile compounds was conducted using ThermoScientific GC-MS system (GC-Trace 1300 equipped with ISQ QD, Single Quadrupole Mass Spectrometer); the GC was equipped with a split mode injector and a TG-5MS capillary column (length $30 \mathrm{~m}$, $0.32 \mathrm{~mm}$ i.d., $0.25 \mu \mathrm{m}$ film thickness). Analysis of compounds was done as described earlier by Barman and Mitra (2019). The identity of compounds was confirmed by calculating the retention indices relative to $\mathrm{C}_{8^{-}}$ $\mathrm{C}_{20}$ n-alkanes. Quantification of compounds was done by external standardization method as described by Majetic and Sinka (2013), using ethyl hexanoate as a known standard. Emitted and endogenous contents of individual scent compound were calculated in nanomole per gram fresh weight of sample using this method: (Peak area of compound $\times$ moles of ethyl hexanoate)/peak area of ethyl hexanoate.

\subsection{Preparation of crude protein extract and assay of phenylalanine ammonia-lyase (PAL) enzyme}

Extraction and assay of PAL enzyme from J. auriculatum flowers was carried out by the method described by Chakraborty et al. (2008) with slight modifications. Briefly, flowers were ground to powder with the help of liquid nitrogen in the presence of $10 \%(\mathrm{w} / \mathrm{w})$ polyvinylpyrrolidone (PVPP). The crude protein was extracted with an extraction buffer comprising of $100 \mathrm{mM}$ Tris $\mathrm{HCl}(\mathrm{pH} 7.5)$ and $10 \mathrm{mM}$ DTT. The slurry was centrifuged at 14,000 r.p.m. for $30 \mathrm{~min}$ at $4^{\circ} \mathrm{C}$. The supernatant obtained was used for assay of PAL activity. The assay mixture contained $100 \mathrm{mM}$ Tris-HCl buffer (pH 7.5), $100 \mu \mathrm{g}$ crude protein, $5 \mathrm{mM}$ L-phenylalanine in a total reaction volume of $250 \mu \mathrm{l}$. After incubating the reaction mixture at $37^{\circ} \mathrm{C}$ for $1 \mathrm{~h}$, the reaction was stopped by addition of an equal volume of methanol: acetic acid (3:1). This was further centrifuged to remove any denatured protein. Formation of in vitro trans -cinnamic acid from L-phenylalanine upon the catalytic activity of PAL was monitored at $275 \mathrm{~nm}$ via a Dionex UltiMate 3000 UHPLC system (Thermo Fisher Scientific, Massachusetts, USA) using Waters ${ }^{\text {TM }}$ Symmetry ${ }^{\mathrm{TM}}$ (Waters, Milford, MA, USA) $\mathrm{C}_{18}$ (3.5 $\mu \mathrm{m}, 75 \mathrm{~mm} \times 4.6 \mathrm{~mm}$ ) reversed-phase column. The mobile phase consists of water (containing $1 \mathrm{mM} \mathrm{TFA}$ ) and methanol at a ratio of 55: $45(\mathrm{v} / \mathrm{v})$ using a constant flow rate of $1 \mathrm{ml} / \mathrm{min}$.

\subsection{Preparations of crude protein extract and assay of phenylacetaldehyde reductase (PAR)} enzyme

Extraction and assay of PAR enzyme from $J$. auriculatum flowers was carried out by the method described by Chen et al. (2011) with slight modifications. Briefly, flowers were ground to powder with the help of liquid nitrogen. The crude protein was extracted with an extraction buffer comprising of $10 \mathrm{mM}$ potassium phosphate buffer ( $\mathrm{pH} 7.5), 1 \%$ glycerol, $5 \mathrm{mM}$ DTT, $0.05 \%$ Triton X and 1mM PMSF. The slurry was centrifuged at 13,000 r.p.m. for $20 \mathrm{~min}$ at $4^{\circ} \mathrm{C}$. The supernatant obtained was used for assay of PAR.

Enzyme activity was determined by catalyzing the reaction of 2-phenylacetaldehyde (1mM) and NADPH $(0.25 \mathrm{mM})$ with crude enzyme extract (containing $100 \mu \mathrm{g}$ of protein), in $10 \mathrm{mM}$ potassium phosphate buffer $(\mathrm{pH} 7)$ at $35^{\circ} \mathrm{C}$ for $30 \mathrm{~min}$. Hexane $(200 \mu \mathrm{l})$ was carefully layered over the aqueous reaction mixture for collecting 2-phenylethanol produced during the reaction. The organic phase containing volatile product was collected and dehydrated using anhydrous sodium sulphate. The formation of 2-phenylethanol (2PE) was monitored using ThermoScientific GC-MS system (GC-Trace 1300 equipped with ISQ QD, Single Quadrupole Mass Spectrometer). The GC was equipped with a TG-5MS capillary column (length $30 \mathrm{~m}, 0.32 \mathrm{~mm}$ i.d., $0.25 \mu \mathrm{m}$ film thickness). The inlet temperature was set at $260^{\circ} \mathrm{C}$. Compounds were separated with the following temperature method: initial oven temperature was set at $60^{\circ} \mathrm{C}$ for $5 \mathrm{~min}$, followed by an increase of $170^{\circ} \mathrm{C}$ at a rate of $20^{\circ} \mathrm{C} / \mathrm{min}$, then a linear increase of $40^{\circ} \mathrm{C} / \mathrm{min}$ to $290^{\circ} \mathrm{C}$, and a final hold of $3 \mathrm{~min}$. Identification and quantification of $2 \mathrm{PE}$ was done by running known quantity of authentic standard.

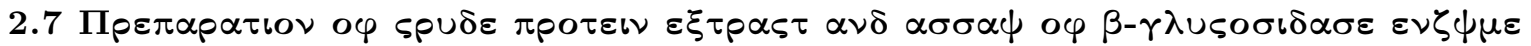

Extraction and assay of $\beta$-glucosidase enzyme from J. auriculatumflowers was carried out by the method described by Reuveni et al. (1999) with slight modifications. Briefly, flowers were ground to powder with the help of liquid nitrogen. The crude protein was extracted with an extraction buffer comprising of $50 \mathrm{mM}$ ascorbic acid, $50 \mathrm{mM}$ Mes, $20 \mathrm{mM}$ DTT, $10 \mathrm{mM} \mathrm{MgCl}_{2}$, $\%$ PVPP, $3 \mathrm{mM}$ PMSF and the $\mathrm{pH}$ was brought to 7.4 with the help of solid Tris. The slurry was centrifuged at 12,000 r.p.m. for 20 min at $4^{\circ} \mathrm{C}$. The 
supernatant obtained was used for assay of $\beta$-glucosidase. The enzyme assay was carried out in $100 \mathrm{mM}$ Citrate buffer ( $\mathrm{pH} 6)$. The cleavage of the substrate p-nitrophenyl- $\beta$-D-gluco-pyranoside (pNGP) by crude enzyme to glycosyl moiety was monitored spectrophotometrically at $400 \mathrm{~nm}$. The increase in absorbance was recorded for estimating the activity of $\beta$-glucosidase.

\subsection{Preparations of crude protein extract and assay of benzyl alcohol: acetyl transferase (BEAT) enzyme}

Extraction and assay of BEAT enzyme from $J$. auriculatum flowers was carried out by the method described by Dudareva et al. (1998) and Bera et al. (2017) with slight modifications. Briefly, flowers were ground to powder with the help of liquid nitrogen. The crude protein was extracted with an extraction buffer (comprising of 2:1 [v/w] buffer/tissue) containing $50 \mathrm{mM}$ BisTris-HCl (pH 6.9), $10 \mathrm{mM} \beta$-mercaptoethanol, $5 \mathrm{mM} \mathrm{Na} 2 \mathrm{~S} 2 \mathrm{O} 5,1 \%$ (w/v) PVPP, and 10\% (v/v) glycerol. The slurry was centrifuged at 12,000 r.p.m. for $20 \mathrm{~min}$ at $4^{\circ} \mathrm{C}$. The supernatant obtained was used for assay of BEAT.

Enzyme activity was determined by catalyzing the reaction of benzyl alcohol (50 $\mathrm{mM})$ and acetyl-Coenzyme A $(1 \mathrm{mM})$ with crude enzyme extract (containing $100 \mu \mathrm{g}$ of protein) in an assay buffer, containing $250 \mathrm{mM}$ Tris- $\mathrm{HCl}[\mathrm{pH} 7.5]$ and $14 \mathrm{mM} \beta$-mercaptoethanol, at $30^{\circ} \mathrm{C}$ for $45 \mathrm{~min}$. Hexane $(200 \mu \mathrm{l})$ was carefully layered over the aqueous mixture for collecting benzyl acetate produced during the reaction. The formation of benzyl acetate was monitored using ThermoScientific GC-MS system (GC-Trace 1300 equipped with ISQ QD, Single Quadrupole Mass Spectrometer). The GC was equipped with a TG-5MS capillary column (length $30 \mathrm{~m}$, $0.32 \mathrm{~mm}$ i.d., $0.25 \mu \mathrm{m}$ film thickness). The inlet temperature was set at $220^{\circ} \mathrm{C}$. Compounds were separated with the following temperature method: initial oven temperature was set at $50^{\circ} \mathrm{C}$ for $2 \mathrm{~min}$, followed by an increase of $5^{\circ} \mathrm{C} / \min$ to $60^{\circ} \mathrm{C}$; hold for $2 \mathrm{~min}$, then a linear increase of $20^{\circ} \mathrm{C} / \min$ to $220^{\circ} \mathrm{C}$; hold for 2 min and then a final increase to $290^{\circ} \mathrm{C}$ at $20^{\circ} \mathrm{C} / \mathrm{min}$ and a hold of $10 \mathrm{~min}$. Identification and quantification of benzyl acetate was done by injecting known quantity of authentic standard in GC-MS system.

\subsection{Preparations of crude protein extract and assay of monoterpene synthase (MTS) enzyme}

Extraction and assay of MTS enzyme from flowers of $J$. auriculatumwas carried out by the method as described by Pichersky et al. (1994) with slight modifications. The crude protein from floral tissue was extracted with an extraction buffer containing $50 \mathrm{mM}$ bis-Tris $\mathrm{HCl}\left(\mathrm{pH} 6.9\right.$ ), $10 \mathrm{mM}$ DTT, $5 \mathrm{mM} \mathrm{Na}_{2} \mathrm{~S}_{2} \mathrm{O}_{5}$, $10 \%(\mathrm{w} / \mathrm{v})$ glycerol and $1 \%(\mathrm{w} / \mathrm{v})$ PVPP.

MTS activity was determined by catalysing the reaction of geranyl pyrophosphate (GPP) (Sigma-Aldrich) $(50 \mu \mathrm{M})$ in assay buffer (containing $50 \mathrm{mM}$ potassium HEPES of pH 7.8, $5 \mathrm{mM} \mathrm{Na}_{2} \mathrm{~S}_{2} \mathrm{O}_{5}, 5 \mathrm{mM}$ DTT and $10 \%$ (w/v) glycerol and $20 \mathrm{mM} \mathrm{MgCl} 2$ and $5 \mathrm{mM} \mathrm{MnCl}_{2}$ as cofactors) with crude enzyme extract (100 $\mu \mathrm{g}$ of protein) at $30^{\circ} \mathrm{C}$ for $60 \mathrm{~min}$. Linalool produced was trapped in hexane $(200 \mu \mathrm{l})$ which was carefully layered over the aqueous reaction mixture. The formation of linalool was monitored using ThermoScientific GC-MS system. The GC was equipped with a DB-5MS column (length $30 \mathrm{~m}, 0.25 \mathrm{~mm}$ i.d., $0.25 \mu \mathrm{m}$ film thickness). The inlet temperature was set at $220^{\circ} \mathrm{C}$. Compounds were separated with the following temperature method: initial oven temperature was set at $50^{\circ} \mathrm{C}$ for $2 \mathrm{~min}$, followed by an increase of $10^{\circ} \mathrm{C} / \mathrm{min}$ to $70^{\circ} \mathrm{C}$; hold for $3 \mathrm{~min}$, then a linear increase of $10^{\circ} \mathrm{C} / \min$ to $200^{\circ} \mathrm{C}$; hold for $2 \mathrm{~min}$ and then a final increase to $300^{\circ} \mathrm{C}$ at $30^{\circ} \mathrm{C} / \mathrm{min}$ and a hold of $10 \mathrm{~min}$. Identification and quantification of linalool was done by injecting known quantity of authentic standard in GC-MS system.

\subsection{0 cDNA preparation and PCR-amplification of partial gene fragments}

Total RNA was extracted from petals $(100 \mathrm{mg})$ of $J$. auriculatumflowers using the TRIzol ${ }^{\circledR}$ reagent

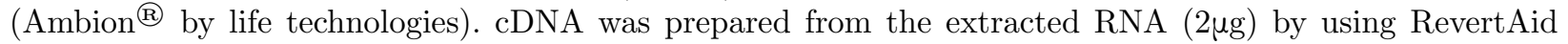
${ }^{\mathrm{TM}}$ M-MuLV reverse transcriptase (ThermoScientific) and oligo $(\mathrm{dT})_{18}$ primer. Gene specific primers for selected volatile pathway enzymes were designed using Primer 3 (v.0.4.0) software from the transcriptome data of a closely related Jasminum species (Li et al., 2015); the gene specific primers for amplification of JaMTS was obtained from partially cloned MTS cDNA fragment as already mentioned in Barman et al. (2020). The primers for amplification of jasmine specific PAL gene (KR869114.1) were obtained from Bera et al. (2017). 
The nucleotide sequences of these primers are listed in supplementary file, Table $\mathbf{S 1}$.

Amplification of these genes from cDNA of $J$. auriculatum was performed via standard semi-quantitative PCR techniques. The primary step of denaturation was maintained at $94^{\circ} \mathrm{C}$ for 3 mins. This was followed by a cyclic reaction involving denaturation at $94^{\circ} \mathrm{C}$ for $45 \mathrm{~s}$, annealing temperature (mentioned in Table S1 ) for $45 \mathrm{sec}$ and extension at $72^{\circ} \mathrm{C}$ for $1 \mathrm{~min}$. Final extension was carried out at $72^{\circ} \mathrm{C}$ for $10 \mathrm{~min}$. All amplified products were confirmed by running in $1.5 \%$ agarose gel. The obtained amplified PCR product was eluted with QIA quick Gel extraction kit (QIAGEN, Germany), dried and sequenced at Eurofins Genomic India Pvt. Ltd. (Bangalore, India) for confirmation of gene. Gene sequences were submitted in GenBank database for obtaining accession numbers.

\subsection{PCR-based gene expression studies}

Expression studies were performed via semi-quantitative PCR and real time quantitative PCR (RT-qPCR) analyses. For semi-quantitative PCR, specific primers (mentioned in Table S1) were used to amplify the core cDNA fragments. The PCR cycles were followed as described in Table S1. PCR amplified products were separated in $1.5 \%$ agarose gel. Gel-images of PCR products were photographed and analysed by ImageJ software to compare the expression levels among the samples using actin as reference gene.

RT-qPCR analysis for amplification of specific end-product genes was performed by the steps as follows: initial denaturation at $94^{\circ} \mathrm{C}$ for $5 \mathrm{~min}$ and then following a cyclic reaction of 40 cycles (denaturation at $94^{\circ} \mathrm{C}$ for $45 \mathrm{~s}$ and annealing at $55^{\circ} \mathrm{C}$ for $1 \mathrm{~min}$ ) using Power SYBR ${ }^{\circledR}$ Green PCR master mix (applied biosystems by life technologies). The relative gene expression level was calculated from the $2^{-\Delta \Delta " \tau}$ method (Schmittgen and Livak, 2008) using actin as the reference gene (Yu et al., 2017), which is constantly expressed in floral tissue of jasmine.

\subsection{Analysis of non-volatile metabolite compounds by GC-MS}

Analysis of non-volatile metabolites was carried out from flowers harvested from plants grown at four different air temperatures in the growth chamber. Extraction and derivatization of metabolites was performed following the method adopted by Agarwal et al. (2018) with minor modifications. Freeze-dried petals (10 $\mathrm{mg}$ ) was powdered and suspended in $300 \mu \mathrm{l}$ ice-cold $80 \%(\mathrm{v} / \mathrm{v})$ methanol. To this $6 \mu \mathrm{l}$ ribitol $(0.4 \mathrm{mg} / \mathrm{ml})$ was added as internal standard. The supernatant was mixed with chloroform and deionized water. The water-methanol phase (polar metabolite fraction) was used for determination of non-volatile compounds. Methoximation of sample was carried out by addition of $20 \mu \mathrm{l}$ methoxyamine hydrochloride $(20 \mathrm{mg} / \mathrm{ml})$ followed by an incubation at $40^{\circ} \mathrm{C}$ for $90 \mathrm{~min}$. Trimethylsilylation of sample was performed by addition of 20 $\mu l N, O$-Bis(trimethylsilyl)trifluoroacetamide (BSTFA) containing 1\% trimethylchlorosilane (TMCS) and subsequently incubated at $80^{\circ} \mathrm{C}$ for $30 \mathrm{~min}$.

The derivatized sample $\left(1 \mu \mathrm{l}\right.$ ) was analyzed on a Trace ${ }^{\mathrm{TM}} 1300$ Gas Chromatograph (Thermo Fisher Scientific, Massachusetts, USA) coupled with an ISQ QD Single Quadrupole Mass Spectrometer. The GC was equipped with a DB-5MS column (length $30 \mathrm{~m}, 0.25 \mathrm{~mm}$ i.d., $0.25 \mu \mathrm{m}$ film thickness). Analysis of metabolites was carried out by the method as described by Kutty and Mitra (2019). Helium was used as the carrier gas where the flow rate of $1 \mathrm{ml} / \mathrm{min}$ was maintained. The $\mathrm{GC}$ inlet temperature was set at $280^{\circ} \mathrm{C}$. Compounds were separated with the following temperature method: initial oven temperature was set at $70^{\circ} \mathrm{C}$ for 1 min, followed by an increase of $2^{\circ} \mathrm{C} / \mathrm{min}$ to $135^{\circ} \mathrm{C}$; hold for $10 \mathrm{~min}$, then a linear increase of $4^{\circ} \mathrm{C} / \mathrm{min}$ to $220^{\circ} \mathrm{C}$; hold for 10 min and then a final increase to $270^{\circ} \mathrm{C}$ at $3.5^{\circ} \mathrm{C} / \mathrm{min}$ and a hold of $20 \mathrm{~min}$. The temperature maintained for MS transfer line and ion source was $290^{\circ} \mathrm{C}$ and $200^{\circ} \mathrm{C}$ respectively. Full scan mode at a scanning range of $\mathrm{m} / \mathrm{z}$ 40-700 a.m.u. was used for recording the mass spectra of compounds. GC-MS raw files were deconvoluted by using Automated Mass Spectral Deconvolution and Identification System (AMDIS) software. Metabolites were identified by comparing the spectral data from the NIST 14 (National Institute of Standards and Technology, Gaithersburg, MD, USA) library. The compounds were confirmed by calculating the retention indices relative to $\mathrm{C}_{8}-\mathrm{C}_{40}$ n-alkanes. The relative abundance of various metabolites was calculated manually in Xcaliber ${ }^{\mathrm{TM}}$ software by calculating the peak area abundance with respect to the internal standard used. 


\subsection{Statistical analysis}

The mean and standard deviation values with a minimum of three replicate data set were calculated using Microsoft Excel 2019. To find the significance of difference amongst the samples, statistical analysis such as Tukey's HSD test was performed using Past3 software $(\mathrm{p}<0.05)$. Principal component analysis (PCA) from metabolite data was achieved via MetaboAnalyst 4.0, an open source software (Xia et al., 2015).

\section{RESULTS}

\subsection{Synthesis and emission of scent from different floral maturation stages under in situ con- dition}

\subsubsection{Scent volatiles variations from in situ flowers}

Benzenoids and terpenoids were shown to be the major volatile compounds emitted from J. auriculatum flowers. To understand variations in emission patterns at different stages of floral growth and maturation until senescence, the contents of major volatiles was evaluated from intact in situ flowers at six defined stages starting from early bud stage to senescence stage. The emission of benzyl alcohol, 2-phenylethanol, linalool and farnesol was highest at flower blooming (S4) stage whereas the emission of benzyl acetate and $\alpha$-farnesene was much higher at fully bloomed (S5) stage (Figure 1 ).

3.1.2 Activities ofmajor pathway enzymes of volatile biosynthesis at different floral maturation stages

To find out any correlation between enzyme activities and scent volatiles synthesis and emission, we attempted to measure the amount of active enzymes (in terms of their in vitro activities) involved in the scent biosynthetic pathways throughout floral lifespan. The major volatile compounds in J. auriculatum are benzyl acetate, 2-phenylethanol and phenylethyl acetate, derived from the phenylpropanoid pathway. PAL is the entry point enzyme of phenylpropanoid pathway that catalyzes the formation oftrans -cinnamic acid from L-phenylalanine. Most of the benzenoid volatile compounds are subsequently formed from trans -cinnamic acid via $\mathrm{C}_{2}$ side chain shortening. Higher PAL activities were recorded at time of flower blooming (S4) stage (Figure 2a), which showed a gradual decline with subsequent stages of petal growth and maturation until senescence. The enzyme BEAT catalyzes the formation of benzyl acetate from the substrate benzyl alcohol in presence of acetyl CoA. Out of the six stages the activity of BEAT was found to be highest at flower blooming (S4) stage (Figure 2c ). The PAR enzyme is responsible for formation of 2-phenylethanol (2PE) from phenylacetaldehyde. Upliftment of PAR activities was observed at late bud stage (S3) which gradually declined after the flower blooms (Figure 2d ). Terpenoid volatiles also contribute to the floral scent bouquet of $J$. auriculatum . Linalool is the major emitted monoterpene compound. The activity of MTS responsible for formation of linalool was also measured; MTS showed highest peak at late bud (S3) stage followed by a gradual decline after flower blooming (S4) (Figure 2e ). Chromatograms indicating product formation by BEAT, PAR and MTS are presented in Figure 2f, $\mathbf{g}, \mathbf{h}$.

Many volatile compounds in J. auriculatum are present as glycosyl-bound form. In this species, it was observed that the release of scent volatiles started at higher rate within first few hours of flower opening. Little is known about the enzymes involved in the de-glycosylation process. The $\beta$-glucosidase activity was measured at different floral maturation stages; a higher activity observed at the flower blooming (S4) stage (Figure 2b ), which indicated the cleavage of glucosyl moiety for easy release of volatile compounds.

\subsubsection{Expression levels of scent related genes at different floral maturation stages}

The levels of transcripts accumulation related to the formation of major scent volatile compounds were studied using semi-quantitative RT-PCR. These include phenylalanine ammonia-lyase ( $J a P A L$ ), acetyl coenzyme A: benzyl alcohol acetyl transferase $(J a B E A T)$ and phenylacetaldehyde reductase (JaPAR ) that are related to the biosynthesis of major benzenoids volatiles, and candidate genes for terpenoid volatiles viz. monoterpene synthase (JaMTS ), 3-hydroxy-3-methylglutaryl coenzyme A synthase ( JaHMGS ), 3-hydroxy3-methylglutaryl coenzyme A synthase $(J a H M G R)$. Further $J a M Y B$, a transcription factor that regulates 
the early steps of benzenoid/phenylpropanoid biosynthesis, and $\beta-\gamma \lambda v$ cosidase gene $(\Theta a \beta \Gamma \lambda v)$ that function to de-glycosylate glucosyl-linked volatiles were also studied. The PCR-amplified transcript bands obtained from cDNA of $J$. auriculatum were sequenced and subsequently blasted to find homologies with the predicted amino acid sequences of the genes available in the public database. The sequence data information for these gene fragments were later submitted to the GenBank databases under accession numbers MT542640, MK879598, MN641835, MK903849, MN641834, MN641833, MK879597 and MK789770 for J. auriculatum respectively.

Transcript abundance of $J a P A L$ and JaBEAT was found to be higher at flower opening (S4) stage. The accumulation of JaPARgene did not vary much within the floral stages apart from a slightly increased abundance at early bud (S1) stage. The levels of JaMYBtranscript accumulation were found to be highest at early bud (S1) stage and gradually declined with the maturity of buds (Figure $\mathbf{3 a}, \mathbf{b}$ ). In order to understand the biosynthesis of terpenoid volatiles, the transcript levels of JaHMGS , JaHMGR (upstream genes involved in the biosynthesis of sesquiterpene volatiles) andJaMTS (the final gene involved in the biosynthesis of monoterpene linalool) were assessed (Figure 3a, b ). It was observed that the transcript level of JaHMGS was highest at mid-bud (S2) stage while late bud (S3) stage showed highest JaHMGR transcript accumulation; the transcript accumulation of JaMTS increased at late bud (S3) stage. Many volatile compounds are biosynthesized and stored as glycosyl bound form. They are further hydrolyzed by several glycolytic enzymes for easy release of volatile compounds. The transcript levels of $\beta$-glucosidase $(\Theta a \beta-\Gamma \lambda v)$ gradually increased from late bud (S3) stage to flower opening (S4) stage and then decreased in the subsequent floral maturation stages.

As volatile compounds namely, benzyl acetate and linalool contribute principally for the signature scent note of $J$. auriculatum flower (Barman et al., 2020), the relative expression of JaBEAT and JaMTS genes were also monitored using real time quantitative PCR (qRT-PCR). The Ct values obtained from qPCR analysis were utilized for calculating the fold change to understand the relative gene expression level (Figure 3c ). It was found that the relative gene expression at different petal growth and maturation stages correlated well with the intensities of the transcripts observed via semi-quantitative RT-PCR.

\subsection{Influence of air temperature conditions on scent volatiles metabolism of $J$. auriculatum flowers}

\subsubsection{Alterations in scent volatile contents due to different air temperature conditions}

Air temperature is a major environmental factor known to influence the biosynthesis and emission of floral scent volatiles. The contents of dominant scent compounds comprising mainly of benzenoid and terpenoid volatiles were monitored with respect to both emitted and endogenous volatiles to understand the influence of temperature on the metabolism accumulation as well as vaporization. Headspace floral volatile collection was done in the evening when the contents of emitted volatiles were in their peaks; GC-MS analysis indicated that the emission of scent compounds first increased then decreased with rise in air temperature (Figure 4, S1 ). Highest emission of benzyl alcohol, benzyl acetate, and cis -jasmone were observed at $25^{\circ} \mathrm{C}$ followed by $30^{\circ} \mathrm{C}$. However, 2-phenylethanol and phenethyl acetate showed higher emission at $30^{\circ} \mathrm{C}$. Emission of indole and other terpene volatiles were highest at $30^{\circ} \mathrm{C}$ followed by $25^{\circ} \mathrm{C}$. Much lower emission of these major floral volatiles was observed both at $20^{\circ} \mathrm{C}$ and $35^{\circ} \mathrm{C}$, the two border-range air temperature set out for the experiments.

The internal pools of floral volatiles were also monitored in terms of free endogenous and glycosylated volatiles to understand the influence of air temperature on the metabolism and storage of scent compounds. While free endogenous volatiles were sampled from flowers after collection of emitted volatiles, we utilized mature buds for sampling of glycosylated volatiles. This is because of the fact that mature buds were reported to contain maximum amount of glycosylated volatiles (Barman and Mitra, 2019). All the major emitted volatile compounds detected from headspace collection were also present as free endogenous volatiles. Further, it was observed that the accumulation of free endogenous volatiles in floral tissues was significantly higher at both $25^{\circ} \mathrm{C}$ and $30^{\circ} \mathrm{C}$ (Figure 5a ). However, the contents were much lower at $20^{\circ} \mathrm{C}$ and $35^{\circ} \mathrm{C}$ as was observed in 
the emission profile. In order to understand the influence of air temperature on the biosynthesis and storage of volatile compounds, we measured the contents of these glycosyl-bound volatiles after removing the bound glycosyl moiety by enzymatic hydrolysis. It was observed that levels of accumulation of aromatic alcohols and monoterpenol volatiles increased with rise in air temperature (up to $30^{\circ} \mathrm{C}$ ) and then followed a sharp decline upon reaching the highest set air temperature $\left(35^{\circ} \mathrm{C}\right)$ for this study (Figure $\mathbf{5 b}$ ).

\subsubsection{Activities ofmajor pathway enzymes of volatile biosynthesis under the influence of tem- perature}

In order to understand the role of temperature on the metabolism of volatile compounds, the activities of a few key enzymes of scent volatiles biosynthesis was studied. Based on the earlier information about the floral stages showing higher activities of particular enzymes under in situ conditions, the crude protein extracts were prepared from floral tissues either at late bud stage or flower blooming stage. The (petal) tissues were collected from different $J$. auriculatum plants grown at different temperature inside the plant growth chamber. Higher in vitro activities of PAL, $\beta$-glucosidase and BEAT were found in J. auriculatumflowers when grown at $25^{\circ} \mathrm{C}$, followed by $30^{\circ} \mathrm{C}$ (Figure 6a-c). High activities of PAR and MTS were recorded both at $25^{\circ} \mathrm{C}$ and $30^{\circ} \mathrm{C}$ temperature regime (Figure $6 \mathbf{d}$, e ). Lower activities of all the above enzymes were detected at $20^{\circ} \mathrm{C}$ and $35^{\circ} \mathrm{C}$, the two border range air temperatures set out for conducting these experiments inside growth chamber. Chromatograms indicating product formation by BEAT, PAR and MTS are presented in Figure 6f, g, h .

\subsubsection{Impact of temperature on scent related genes}

To check whether elevated air temperature regime affects the end products of scent pathway, the expression levels of gene-encoding enzymes responsible for the formation of volatile compounds were evaluated. Based on earlier information about the higher transcript accumulation levels in J. auriculatum flowers under in situ condition, extractions of total RNAs were made from flowers of $J$. auriculatum plant grown at four different air temperatures as defined earlier with at least two/three biological replication.

It was observed that expression levels of $J a \mathrm{PAL}, J a B E A T$ were high in flowers of $J$. auriculatum grown at $25^{\circ} \mathrm{C}$; the accumulation of $J a M T S$ transcript was higher at both $25^{\circ} \mathrm{C}$ and $30^{\circ} \mathrm{C}$ while the accumulation of $J a P A R$ was highest at $30^{\circ} \mathrm{C}$ (Figure 7a, b ). The relative expression levels of JaBEAT and JaMTS monitored via RT-qPCR correlated well with semi-quantitative RT-PCR results (Figure 7c ). Elevated accumulations of $J a H M G S$ and $J a H M G R$ transcripts were observed at both $25^{\circ} \mathrm{C}$ and $30^{\circ} \mathrm{C}$. Successive upliftmenst of $\Theta a \beta$ -

$\Gamma \lambda$ vand $J a M Y B$ transcripts were observed in flowers of $\mathrm{J}$. auriculatum grown at $25^{\circ} \mathrm{C}$ followed by $30^{\circ} \mathrm{C}$ air temperature. The expression levels of all these genes were much lower at air temperatures of $20^{\circ} \mathrm{C}$ and $35^{\circ} \mathrm{C}$.

\subsubsection{Influence of temperature onaccumulation of non-volatile metabolite compounds}

Different groups of non-volatile metabolites were identified from polar floral extracts. Mature buds fromJ. auriculatum plants growing under different temperature regime were collected and subsequently freeze-dried aiming at obtaining the maximum recovery of non-volatile metabolites. Compounds comprising mainly of primary metabolites such as, sugars, organic acids, fatty acids and other specialized metabolites (mainly phenolic acids) which are non-volatile in nature were detected as derivatized metabolites from lyophilized flowers. These metabolites were compared from plants grown at different temperatures to monitor any significant perturbations that might have occurred in the primary metabolism. In total, 37 metabolites were identified from GC-MS chromatogram (Figure S2, Table S2). The contents of these metabolites are represented in the form of a heatmap illustration with colour gradation to signify the changes under different air temperature regime (Figure 8a ). An overall reduction in the contents of non-volatile metabolites was observed at $20^{\circ} \mathrm{C}$, the lower range border air temperature set out for this study. Enhanced accumulations of most of the sugar metabolites viz. fructose, glucose, lactose, lactulose, gentiobiose and mannobiose were observed in flowers of $\mathrm{J}$. auriculatum grown at $25^{\circ} \mathrm{C}$ subsequently followed by $30^{\circ} \mathrm{C}$. Enhanced abundance of benzenoid precursors such as, coutaric acid, caffeic acid and shikimic acid were found in flowers of $J$. auriculatum plant grown at $25^{\circ} \mathrm{C}$; the content of 4-hydroxy benzyl alcohol was also found to be highest in flowers of $30^{\circ} \mathrm{C}$ temperature grown plants followed by $25^{\circ} \mathrm{C}$. The contents of most of these detected phenolics 
were however low both at $20^{\circ} \mathrm{C}$ and $35^{\circ} \mathrm{C}$. Further the relative abundance of mevalolactone, the lactone form of mevalonic acid (which serves as precursor for biosynthesis of sesquiterpenes), was found to be highest in flowers of $J$. auriculatum plant grown at $30^{\circ} \mathrm{C}$. The abundance of major organic acids was highest in plants growing at $30^{\circ} \mathrm{C}$. At $35^{\circ} \mathrm{C}$, diversion of metabolites from volatile pathway towards sugar alcohols viz. fucitol, glucitol and myo-inositol was observed. PCA was carried out upon using the metabolites as variables (Figure 8b, c ). A clear segregation of all temperature treated samples was observed with well clustered individual sample replicate. According to score plot, treatments at $25^{\circ} \mathrm{C}$ and $30^{\circ} \mathrm{C}$ were closer on the $\mathrm{PC} 1$ axis. However, the plants grown at $20^{\circ} \mathrm{C}$ and $35^{\circ} \mathrm{C}$, (the two border-range air temperatures set out for conducting these experiments) had some proximity as observed in terms of PC2.

\section{DISCUSSION}

Benzenoid and terpenoid volatiles dominate the floral scent note in summer-blooming J. auriculatum (Bera et al., 2015). The present study suggest that contents of the major scent compounds were high at Stages 4 and 5 when the flowers start unfurling and becomes fully open under in situ conditions. The sampling time for S4 was between 5-6 pm in the evening and S5 was between 8-9 pm at night. These results agreed well with our recent finding where highest temporal emission was between 6-10 pm at night, where sampling was done at $4 \mathrm{~h}$ interval (Barman and Mitra., 2019). The findings of our result also correspond well with the findings of other summer jasmines where the maximum emission was observed at late night on the same day of flower blooming (Bera et al., 2017; Pragadheesh et al., 2017; Yu et al., 2017). These findings show that this species is nocturnally active to attract night pollinators (Paul et al., 2019).

In order to understand the metabolism of major emitted volatiles comprising benzenoids (benzyl acetate, 2phenylethanol and benzyl alcohol) and terpenoids (linalool, $\alpha$-farnesene and farnesol), an attempt was made to study the pathway enzymes and genes which contribute to the biosynthesis of these volatile compounds at different floral maturation stages. The biosynthesis and emission of volatiles from J. auriculatum flowers showed a floral growth and maturation specific pattern. The enzyme PAL is generally known as the rate limiting enzyme in the benzenoid/phenylpropanoid biosynthesis pathway. The gene expression and enzyme activity levels of PAL correlated well with the benzenoids emission. A similar observation in the enhanced rate of PAL expression and activity was also observed in petunia and tuberose that correlated with their benzenoids emission (Cheng et al., 2016; Maiti and Mitra, 2017). The gene expression level and activity of BEAT, the ultimate enzyme for benzyl acetate formation was high at flower blooming stage. This result suggest that highest rate of biosynthesis takes place when flower starts blooming and the compound formed is present as inter pool in the floral tissue with some basal emission at this stage and maximum emission occurs when flower was fully bloomed. The compound benzyl acetate is reported to be emitted in higher rate at night to attract nocturnal pollinators (Dudareva et al., 1998). The variations observed in BEAT enzyme activity at different stages of petal growth and maturation are similar to those observed by Bera et al. (2017) in J. sambac where BEAT activity reached its peak on the same day of maximum emission. Shalit et al. (2003) has also reported a maximal activity of acetyl-transferase at a stage prior to the stage where maximum acetate ester volatile emission was observed from petals of rose. The higher enzyme activity of PAR and MTS at stage 3 indicated that biosynthesis of 2-phenylethanol and linalool was maximum at the bud stage where no emission of these compounds was detected; however high emission of 2-phenylethanol and linalool was detected when the flower started blooming. It was reported earlier that these compounds were present as glycosyl-linked volatile in floral tissue (Watanabe et al., 1993; Oka et al., 1999). It can be inferred that these compounds after biosynthesis was glycosylated prior to their storage in floral tissue, and upon flower opening emission of these de-glycosylated volatiles occurs. PAR activity was highest at mature bud stage and a high abundance of this gene occurred throughout the floral lifespan unlike the results obtained from enzyme activity. The plausible reason might be that the transcript accumulation is active at different stages of petal growth and maturity, but due to lack of substrates the enzyme activity was limited to late bud stage. Gene expression levels of JaMTSalso correlated well with the activities of its corresponding enzyme. We reported earlier that higher content of glycosylated volatiles was present in mature buds of J. auriculatum (Barman and Mitra, 2019); in this study we found that upon flower opening the stored glycosylated volatiles get released as free volatiles by the action of $\beta$-glucosidase as evidenced by enhanced transcript levels and 
uplifted $\beta$-glucosidase enzyme activity. This suggests that $\beta$-glucosidase plays an important role in scent production by hydrolysis of glycosyl moiety attached to volatile molecule in $J$. auriculatum . Thus, upon flower opening the scent emission is enhanced due to increased hydrolytic activity. Similar observation was reported fromNarcissus flowers where $\beta$-glucosidase activity correlated with the increase in scent emission by cleaving the glucosyl bound volatiles from open flowers (Reuveni et al., 1999).

Higher expressions of JaHMGS and JaHMGR at stage 2 and stage 3 indicated that these upstream genes start expressing at bud stages for formation of precursors for sesquiterpene volatiles biosynthesis. A similar observation in other scented Jasminumspecies has been reported earlier (Yu et al., 2017). Higher expression levels of $J a M Y B$ at stage 1 indicates that these TFs has a role in regulation of upstream genes responsible for phenylpropanoid biosynthesis at early bud stage. This TF belonging to R2R3 family upregulates the early steps of phenylpropanoid/benzenoid biosynthesis (Liu et al., 2015). R2R3 TFs has also been reported to enhance aroma production by regulating the biosynthesis of phenylpropanoids in tomato, maize and other scented flowering plants (Jian et al., 2019; Liu et al., 2015; Ramya et al., 2018).

Apart from different developmental, temporal and spatial patterns, different environmental factors also influence the accumulation of specialized volatile metabolites in plants (Cheng et al., 2016). In the past decades the impact of varying air temperature out of all other environmental factors has been reported to have significant influence on the scent emission from many commercially important flowers (Hu et al., 2013; Cna'ani et al., 2015; Zeng et al., 2019). However, no detailed reports are available on the emission of volatiles from any Jasminum species, a commercially important flowering species in tropical countries. In the present study it was observed that the contents of most of the compounds comprising benzenoid and terpenoid volatiles was high either at $25^{\circ} \mathrm{C}$ or $30^{\circ} \mathrm{C}$. At $20^{\circ} \mathrm{C}$ and $35^{\circ} \mathrm{C}$, air temperatures, much lower contents of emitted and endogenous volatiles were recorded. The decrease in both emitted and endogenous floral volatile contents at the two border-range air temperatures (set out for conducting growth chamber experiments) conditions indicates that ambient temperature affects both metabolism and vaporization of the compounds. A schematic diagram in Figure 9 provides holistic overview about the influence of different air temperatures on emission of major floral volatiles in $J$. auriculatum. The release of scent volatiles from T. repens (Jakobsen and Olsen 1994) and P. hybrida (Sagae et al., 2008) flowers increased with increase in temperature up to $35^{\circ} \mathrm{C}$. It was also reported that emission of volatiles from $P$. hybrida flowers was low at $20^{\circ} \mathrm{C}$ but with high contents of endogenous volatiles accumulation at the same temperature (Sagae et al., 2008) unlike the findings observed by us. The plausible reason for this reduced metabolism inJ. auriculatum flowers at $20^{\circ} \mathrm{C}$ might be because of its tropical adaption which made the genetic makeup changed in such a way that would support the maximum production of floral scent upon growing under a temperature range of $25^{\circ} \mathrm{C}$ to $30^{\circ} \mathrm{C}$. A recent study conducted on emission of scent from cut rose revealed that an increased release of benzenoid volatiles was observed at $30^{\circ} \mathrm{C}$ unlike the contents observed under $5^{\circ} \mathrm{C}$ and $15^{\circ} \mathrm{C}$ (Zeng et al., 2019).

Environmental conditions not only affect the vaporization of volatile compounds from flowers, but also the biosynthesis, particularly under different air temperature regimes (Cheng et al., 2016). In this study we observed that the contents of both emitted and endogenous volatiles in J. auriculatum flowers were modulated under temperature regime, suggesting an important role of temperature on volatiles metabolism. To establish the hypothesis, the amount of active enzymes in the floral volatiles pathway was measured in terms of their in vitroactivities from flowers of $J$. auriculatum growing under different air temperature regime. Activities of BEAT, PAR, MTS and $\beta$-glucosidase corresponded well with the contents of their respective volatiles as observed at different stages of floral maturation. Expression analysis of genes also supported the in vitro activities data. Similar observations were found with the reduced contents of benzenoid volatiles in P. hybrida flowers where incubation of this plant at higher air temperature led to downregulation of scent related genes (Cna'ani et al., 2015). Downregulation of emitted volatiles originating from benzenoid/phenylpropanoid pathway was observed when air temperature reached at $35^{\circ} \mathrm{C}$. To understand this phenomenon, we attempted to study expression pattern and activity of PAL, the first enzyme in the phenylpropanoid pathway leading to the formation of many phenolic compounds including benzenoid volatiles and anthocyanins. Reduced enzyme activity as well as gene expression of PAL at $20^{\circ} \mathrm{C}$ and $35^{\circ} \mathrm{C}$ was well supported by previous finding 
where too low or too high ambient temperature hindered the activity of this enzyme (Shaked-Sachray et al., 2002). The expression levels of most of the intermediate genes (JaHMGS, JaHMGR ) as well as the JaMYB , R2R3 family transcription factor also corelated well with the contents of floral scent under different air temperature condition. Similar findings in P. hybrida and R. hybrida flowers were reported earlier where too low or too high ambient temperature affected the transcript levels of intermediate genes responsible for the biosynthesis of volatile compounds (Cheng et al., 2016; Zeng et al., 2019). Our present findings suggest that air temperature range of $25^{\circ} \mathrm{C}$ followed by $30^{\circ} \mathrm{C}$ aids in the maximal release of floral scent from $\mathrm{J}$. auriculatum . The floral volatiles metabolism and emission were shown at first to increase and then decreased with the enhanced air temperature regime. Similar observation was also found in Lilium flowers, where floral scent upsurge with increase in temperature, followed by a gradual decrease was recorded (Hu et al., 2013). Lower release of volatiles at $20^{\circ} \mathrm{C}$ might be because of reduced enzyme activity responsible for biosynthesis of floral scent as was observed in our study. An increased temperature of $35^{\circ} \mathrm{C}$ inhibited the expression of pathway genes which finally resulted in reduced activity of end product enzymes responsible for the biosynthesis as well as emission of scent volatiles from J. auriculatum flowers. Reduced emission of floral scent at higher temperatures of $35^{\circ} \mathrm{C}$ was also reported from P. axillarisflowers (Sagae et al., 2008).

Non-volatile metabolites identified from floral extracts comprised mainly of primary metabolites viz. sugars, organic acids, fatty acids and a few secondary metabolites like phenolic acids. The higher abundance of monosaccharides mainly fructose, glucose and arabinose under $25^{\circ} \mathrm{C}$ supports well with the findings observed from volatile contents under different temperature conditions. These monosaccharides are the ultimate precursors for most of the biosynthetic pathways involved in the biosynthesis of floral volatiles (Pickersky et al., 2006). Therefore, enhanced contents of these primary metabolites indicate not only the downstream precursors (phenolic acids) but also the upstream precursors (eg. monosaccharides) are affected by variations in air temperature conditions. Our findings suggest an increased content of most of the observed sugar alcohols under the upper border-range temperature of $35^{\circ} \mathrm{C}$. This may be due to the fact that at this temperature the plants might have shifted its carbon pool to synthesize sugar alcohols rather than biosynthesis of specialized scent molecules to protect themselves from mild heat stress. It was earlier reported that sugar alcohols are used as osmoprotectants and usually accumulated in plants facing many kinds of abiotic stresses (Tarczynski et al., 1993; Sheveleva et al., 1998). It was also observed that the abundance of most of the phenolic acids and other intermediate precursors was highest under the temperature where highest scent emission rate was observed. Increased amount of these precursors supports the increased scent compound formation under $25^{\circ} \mathrm{C}$ and $30^{\circ} \mathrm{C}$.

\section{CONCLUSIONS}

In this study, through a series of experiments conducted, we gained an insight into the different enzymatic pathways forming a diverse range of volatile end products, that together constitute the unique fragrance note of $J$. auriculatum flowers dominated by benzenoid and terpenoid compounds. Our results suggest that the synthesis and emission of scent volatiles in this species is predominant in a specific floral maturation stage of this short span flower. We also demonstrated that changes in air temperature modulate the scent emission in $J$. auriculatum flowers. Such knowledge may provide new clues for cultivation of J. auriculatumunder air-cooled polyhouse condition for better productivity in terms of harvesting of scent compounds.

\section{ACKNOWLEDGEMENTS}

This work was supported by an extramural grant [38(1420)/16/ EMR-II to A Mitra] from the Council of Scientific and Industrial Research (CSIR; www.csirhrdg.res.in), India. M Barman was a recipient of institute doctoral fellowship.

\section{REFERENCES}

Agarwal, A., Gupta, S. D., Barman, M., \& Mitra, A. (2018). Photosynthetic apparatus plays a central role in photosensitive physiological acclimations affecting spinach (Spinacia oleraceaL.) growth in response to blue and red photon flux ratios. Environmental and Experimental Botany , 156 , 170-182. 
Barman, M., \& Mitra, A. (2019). Temporal relationship between emitted and endogenous floral scent volatiles in summer-and winter-blooming Jasminum species. Physiologia Plantarum , 166 , 946-959.

Barman, M., Kotamreddy, J. N. R., Agarwal, A., \& Mitra, A. (2020). Enhanced emission of linalool from floral scent volatile bouquet in Jasminum auriculatum variants developed via gamma irradiation. Industrial Crops and Products , 152, 112545.

Bera, P., Kotamreddy, J. N. R., Samanta, T., Maiti, S., \& Mitra, A. (2015). Inter-specific variation in headspace scent volatiles composition of four commercially cultivated jasmine flowers. Natural Product Research , 29 , 1328-1335.

Bera, P., Mukherjee, C., \& Mitra, A. (2017). Enzymatic production and emission of floral scent volatiles in Jasminum sambac . Plant Science, 256, 25-38.

Chakraborty, D., Sircar, D., \& Mitra, A. (2008). Phenylalanine ammonia-lyase-mediated biosynthesis of 2-hydroxy-4-methoxybenzaldehyde in roots of Hemidesmus indicus . Journal of Plant Physiology , 165, 1033-1040.

Chen, X.M., Kobayashi, H., Sakai, M., Hirata, H., Asai, T., Ohnishi, T., Baldermann, S. \& Watanabe, N. (2011). Functional characterization of rose phenylacetaldehyde reductase (PAR), an enzyme involved in the biosynthesis of the scent compound 2-phenylethanol. Journal of Plant Physiology , 168 , 88-95.

Cheng, S., Fu, X., Mei, X., Zhou, Y., Du, B., Watanabe, N., \& Yang, Z. (2016). Regulation of biosynthesis and emission of volatile phenylpropanoids/benzenoids in petunia $\mathrm{x}$ hybrida flowers by multi-factors of circadian clock, light, and temperature. Plant Physiology and Biochemistry , 107, 1-8.

Cna'ani, A., Muehlemann, J. K., Ravid, J., Masci, T., Klempien, A., Nguyen, T. T., Dudareva, N., Pichersky, E. \& Vainstein, A. (2015).Petunia x hybrida floral scent production is negatively affected by high-temperature growth conditions. Plant, Cell $\&$ Environment , 38 , 1333-1346.

Dement, W. A., Tyson, B. J., \& Mooney, H. A. (1975). Mechanism of monoterpene volatilization in Salvia mellifera. Phytochemistry, 14, 2555-2557.

Dudareva, N., Raguso, R. A., Wang, J., Ross, J. R., \& Pichersky, E. (1998). Floral scent production in Clarkia breweri : III. Enzymatic synthesis and emission of benzenoid esters. Plant Physiology , 116 , 599-604.

Dudareva, N., D'auria, J. C., Nam, K. H., Raguso, R. A., \& Pichersky, E. (1998). Acetyl-CoA: benzylalcohol acetyltransferase-an enzyme involved in floral scent production in Clarkia breweri . The Plant Journal , 14 , 297-304.

Dudareva, N., Klempien, A., Muhlemann, J. K., \& Kaplan, I. (2013). Biosynthesis, function and metabolic engineering of plant volatile organic compounds. New Phytologist , 198 , 16-32.

Edris, A. E., Chizzola, R., \& Franz, C. (2008). Isolation and characterization of the volatile aroma compounds from the concrete headspace and the absolute of Jasminum sambac (L.) Ait. (Oleaceae) flowers grown in Egypt. European Food Research and Technology , 226 , 621.

Fu, J., Hou, D., Zhang, C., Bao, Z., Zhao, H., \& Hu, S. (2017). The emission of the floral scent of four Osmanthus fragrans cultivars in response to different temperatures. Molecules, 22 , 430.

Gupta, G. N., \& Chandra, G. (1957) Indian Jasmine. Economic Botany , 11 , 178-181.

Helsper, J. P., Davies, J. A., Bouwmeester, H. J., Krol, A. F., \& van Kampen, M. H. (1998). Circadian rhythmicity in emission of volatile compounds by flowers of Rosa hybrida L. cv. Honesty.Planta , 207, $88-95$.

Hendel-Rahmanim, K., Masci, T., Vainstein, A., \& Weiss, D. (2007). Diurnal regulation of scent emission in rose flowers. Planta, 226 , 1491-1499. 
Hu, Z., Zhang, H., Leng, P., Zhao, J., Wang, W., \& Wang, S. (2013). The emission of floral scent from Lilium 'siberia'in response to light intensity and temperature. Acta Physiologiae Plantarum, 35 , 1691-1700.

Irmisch, S., Krause, S. T., Kunert, G., Gershenzon, J., Degenhardt, J., \& Kollner, T. G. (2012). The organ-specific expression of terpene synthase genes contributes to the terpene hydrocarbon composition of chamomile essential oils. BMC Plant Biology , 12, 84.

Ito, Y., Sugimoto, A., Kakuda, T., \& Kubota, K. (2002). Identification of potent odorants in Chinese jasmine green tea scented with flowers ofJasminum sambac. Journal of Agricultural and Food Chemistry, $50,4878-4884$.

Jakobsen, H. B., \& Olsen, C. E. (1994). Influence of climatic factors on emission of flower volatiles in situ. Planta, 192, 365-371.

Jian, W., Cao, H., Yuan, S., Liu, Y., Lu, J., Lu, W., Li, N., Wang, J., Zou, J., Tang, N., Xu, C., Cheng, Y., Gao, Y., Xi, W., Bouzayen, M., \& Li, Z., 2019. SlMYB75, an MYB-type transcription factor, promotes anthocyanin accumulation and enhances volatile aroma production in tomato fruits. Horticulture Research $, 6,1-15$.

Joulain, D., \& Laurent, R. (1995). The absolute from flowers ofJasminum auriculatum Vahl. from India. Flavour and Fragrance Journal , 10 , 193-197.

Kolosova, N., Gorenstein, N., Kish, C. M., \& Dudareva, N. (2001). Regulation of circadian methyl benzoate emission in diurnally and nocturnally emitting plants. The Plant Cell , 13 , 2333-2347.

Kuroda, K., Inoue, N., Ito, Y., Kubota, K., Sugimoto, A., Kakuda, T., \& Fushiki, T. (2005). Sedative effects of the jasmine tea odor and (R)-(-)-linalool, one of its major odor components, on autonomic nerve activity and mood states. European Journal of Applied Physiology ,95 , 107-114.

Kutty, N. N., \& Mitra, A. (2019). Profiling of volatile and non-volatile metabolites in Polianthes tuberosa L. flowers reveals intraspecific variation among cultivars. Phytochemistry , 162 , 10-20.

Li, Y. H., Zhang, W., \& Li, Y. (2015). Transcriptomic analysis of flower blooming in Jasminum sambac through de novo RNA sequencing. Molecules , 20 , 10734-10747.

Liu, J., Osbourn, A., \& Ma, P. (2015). MYB transcription factors as regulators of phenylpropanoid metabolism in plants. Molecular Plant , 8 , 689-708.

Maiti, S., \& Mitra, A. (2017). Morphological, physiological and ultrastructural changes in flowers explain the spatio-temporal emission of scent volatiles in Polianthes tuberosa L. Plant 85 Cell Physiology , 58 , 2095-2111.

Majetic, C. J., \& Sinka, B. N. (2013). Diverging pathways: differential benzenoid and phenylpropanoid volatile production in Phlox subulata L. cultivars. Biochemical Systematics and Ecology , 50 , 75-81.

Muhlemann, J. K., Klempien, A., \& Dudareva, N. (2014). Floral volatiles: from biosynthesis to function. Plant, Cell \& Environment, 37 , 1936-1949.

Oka, N., Ohishi, H., Hatano, T., Hornberger, M., Sakata, K., \& Watanabe, N. (1999). Aroma evolution during flower opening in Rosa damascena Mill. Zeitschrift fur Naturforschung C , 54, 889-895.

Oyama-Okubo, N., Ando, T., Watanabe, N., Marchesi, E., Uchida, K., \& Nakayama, M. (2005) Emission mechanism of floral scent in Petunia axillaris . Bioscience, Biotechnology, and Biochemistry69 , 773-777.

Paul, I., Chatterjee, A., Maiti, S., Bhadoria, P B S., \& Mitra, A. (2019) Dynamic trajectories of volatile and non-volatile specialised metabolites in 'overnight' fragrant flowers of Murraya paniculata . Plant Biology , 21, 899-910. 
Pichersky, E., Raguso, R. A., Lewinsohn, E., \& Croteau, R. (1994). Floral scent production in Clarkia (Onagraceae) (I. Localization and developmental modulation of monoterpene emission and linalool synthase activity). Plant Physiology , $106,1533-1540$.

Pragadheesh, V. S., Chanotiya, C. S., Rastogi, S., \& Shasany, A. K. (2017). Scent from Jasminum grandiflorum flowers: Investigation of the change in linalool enantiomers at various developmental stages using chemical and molecular methods. Phytochemistry , 140 , 83-94.

Ramya, M., An, H. R., Baek, Y. S., Reddy, K. E., \& Park, P. H. (2018). Orchid floral volatiles: Biosynthesis genes and transcriptional regulations. Scientia Horticulturae , 235 , 62-69.

Raguso, R. A., \& Pichersky, E. (1995). Floral volatiles from Clarkia breweri and C. concinna (Onagraceae): Recent evolution of floral scent and moth pollination. Plant Systematics and Evolution, 194, 55-67.

Reuveni, M., Sagi, Z., Evnor, D., \& Hetzroni, A. (1999). $\beta$-Glucosidase activity is involved in scent production in Narcissus flowers.Plant Science, 147, 19-24.

Sagae, M., Oyama-Okubo, N., Ando, T., Marchesi, E. \& Nakayama, M. (2008). Effect of temperature on the floral scent emission and endogenous volatile profile of Petunia axillaris .Bioscience, Biotechnology, and Biochemistry, 72 , 110-115.

Schmittgen, T. D., \& Livak, K. J. (2008). Analyzing real-time PCR data by the comparative $\mathrm{C}_{\mathrm{T}}$ method. $N a-$ ture Protocols , 3 , 1101-1108.

Schuurink, R. C., Haring, M. A., \& Clark, D. G. (2006). Regulation of volatile benzenoid biosynthesis in petunia flowers. Trends in Plant Science, 11 , 20-25.

Shaked-Sachray, L., Weiss, D., Reuveni, M., Nissim-Levi, A., \& Oren-Shamir, M. (2002). Increased anthocyanin accumulation in aster flowers at elevated temperatures due to magnesium treatment. Physiologia Plantarum, 114, 559-565.

Shalit, M., Guterman, I., Volpin, H., Bar, E., Tamari, T., Menda, N., Adam, Z., Zamir, D., Vainstein, A., Weiss, D. \& Pichersky, E. (2003). Volatile ester formation in roses. Identification of an acetyl-coenzyme A. Geraniol/citronellol acetyltransferase in developing rose petals. Plant Physiology , 131 , 1868-1876.

Sheveleva, E. V., Marquez, S., Chmara, W., Zegeer, A., Jensen, R. G., \& Bohnert, H. J. (1998). Sorbitol6-phosphate dehydrogenase expression in transgenic tobacco: high amounts of sorbitol lead to necrotic lesions. Plant Physiology, 117, 831-839.

Tarczynski, M. C., Jensen, R. G., \& Bohnert, H. J. (1993). Stress protection of transgenic tobacco by production of the osmolyte mannitol. Science, 259 , 508-510.

Watanabe, N., Watanabe, S., Nakajima, R., Moon, J. H., Shimokihara, K., Inagaki, J., Etoh, H., Asai, T., Sakata, K. \& Ina, K. (1993). Formation of flower fragrance compounds from their precursors by enzymic action during flower opening. Bioscience, Biotechnology, and Biochemistry , 57, 1101-1106.

Wei, A., \& Shibamoto, T. (2007). Antioxidant activities and volatile constituents of various essential oils. Journal of Agricultural and Food Chemistry , 55 , 1737-1742.

Xia, J., Sinelnikov, I. V., Han, B., \& Wishart, D. S. (2015). MetaboAnalyst 3.0-making metabolomics more meaningful. Nucleic Acids Research , 43 , 251-257.

Yu, Y., Lyu, S., Chen, D., Lin, Y., Chen, J., Chen, G., \& Ye, N. (2017). Volatiles emitted at different flowering stages ofJasminum sambac and expression of genes related to $\alpha$-farnesene biosynthesis. Molecules , 22, 546 .

Zeng, L., Wang, X., Dong, F., Watanabe, N., \& Yang, Z. (2019). Increasing postharvest high-temperatures lead to increased volatile phenylpropanoids/benzenoids accumulation in cut rose (Rosa hybrida) flowers. Postharvest Biology and Technology , 148, 68-75. 


\section{FIGURE CAPTIONS}

Figure 1. Emission of benzenoid (a-c) and terpenoid (d-f) volatiles from J. auriculatumflowers during their lifespan, grown under in situ condition. Emitted volatiles were measured by headspace collection from intact flowers at six different floral maturation stages i.e. from green bud to senescence. Histogram represent the average values of three to five independent experimental setup where SD is represented in vertical lines. Data indicated with different alphabets differ significantly according to Tukey's HSD $(p<0.05)$. The collection of volatiles was carried out in a glass headspace for an hour.

Figure 2. Changes in the amount of active proteins (in terms of their in vitro activities) of key enzymes for biosynthesis of phenylpropanoids/benzenoids/terpenoids volatiles in flowers of J. auriculatum collected at different floral maturation stages. Levels of PAL specific activity responsible for biosynthesis oftrans -cinnamic acid at different bud and flowering stages (a). Levels of $\beta$-glucosidase specific activity responsible for hydrolysis of glycosyl bound volatiles at different bud and flowering stages (b). Levels of BEAT specific activity responsible for biosynthesis of benzyl acetate at different bud and flowering stages (c). Levels of PAR specific activity responsible for biosynthesis of 2-phenylethanol at different bud and flowering stages (d). Levels of MTS specific activity responsible for biosynthesis of linalool at different bud and flowering stages (e). GC chromatogram showing the product formation catalysed by BEAT (f), PAR (g) and MTS (h) enzymes extracted from flowers of different developmental stages where product formation and substrate are marked, IS indicates internal standard used. Histograms represent the average values of three to five independent experimental setup where SD is represented in vertical lines. Data indicated with different alphabets differ significantly according to Tukey's HSD $(p<0.05)$.

Figure 3. Expression of candidate genes of scent biosynthetic pathway at different floral maturation stages of $J$. auriculatum . Agarose gel images of amplified PCR products for $\Theta a \Pi A \Lambda, \Theta a B E A T, \Theta a \Pi A P, \Theta a M \Psi B$, $\Theta a \beta-\Gamma \lambda v, \Theta a H M \Gamma \Sigma, \Theta a H M \Gamma P, \Theta a M T \Sigma$ (a). Color codes indicate the relative expression analysis of scent related genes by semi-quantitative RT-PCR with actin as the internal standard at six stages of floral maturation, where lower intensity is indicated in green and higher intensity is indicated in red (b). qPCR analyses of $J a B E A T$ and JaMTS, the ultimate genes responsible for the biosynthesis of benzyl acetate and linalool, respectively, the major scent contributors in J. auriculatum (c). Values are represented as mean of three individual replicates where vertical lines indicate the SD. Data indicated with different alphabets differ significantly according to Tukey's HSD $(p<0.05)$.

Figure 4. Altered emission of scent volatiles from J. auriculatum flowers grown under a range of fixed temperatures in growth chamber. Plants were simultaneously grown under four different air temperature conditions viz. 20, 25, 30 and $35{ }^{\circ} \mathrm{C}$. Emitted volatiles were collected on the day of blooming from the headspace of intact flowers collected individually in the evening between 6.00 p.m. to 7.00 p.m. Values are represented as mean of three individual experimental setups where vertical lines indicate the SD. Data indicated with different alphabets differ significantly according to Tukey's HSD $(p<0.05)$.

Figure 5. Variations in the content of internal pool of scent volatiles in the form of free-endogenous and glycosyl-bound compounds in J. auriculatum flowers grown under different air temperature regime. Plants were grown under four different temperature conditions viz. 20, 25, 30 and $35{ }^{\circ} \mathrm{C}$. Sampling of free endogenous volatiles were done from these flowers used earlier for collection of emitted volatiles. Petals were immediately excised and extracted with dichloromethane for immediate release of the internal free scent molecules by organic solvent. The sampling of glycosylated volatiles was carried out from petals of mature buds by enzymatic treatment for hydrolysis of glycosyl moiety from attached volatile compound. Values are represented as mean of three individual replicates where vertical lines indicate the SD. Data indicated with different alphabets differ significantly according to Tukey's HSD $(p<0.05)$.

Figure 6. Levels of specific activities of key enzymes responsible for biosynthesis of phenylpropanoids/ benzenoids/terpenoids in flowers of $J$. auriculatum collected from plants growing under a range of air temperature conditions. Plants were grown under four different air temperature conditions viz. $20^{\circ} \mathrm{C}, 25^{\circ} \mathrm{C}, 30^{\circ} \mathrm{C}$ and $35{ }^{\circ} \mathrm{C}$. Levels of PAL specific activity responsible for biosynthesis of trans-cinnamic acid from flowers 
kept under different temperature conditions (a). Levels of $\beta$-glucosidase specific activity responsible for hydrolysis of glycosyl bound volatiles from flowers kept under different temperature conditions (b). Levels of BEAT specific activity responsible for biosynthesis of benzyl acetate from flowers kept under different temperature conditions (c). Levels of PAR specific activity responsible for biosynthesis of 2-phenylethanol from flowers kept under different temperature conditions (d). Levels of MTS specific activity responsible for biosynthesis of linalool from flowers kept under different temperature conditions (e). The crude extracts for activity studies of particular enzymes under different temperature were collected either at late bud stage or at flower blooming stage depending on the higher content of particular enzymes as was observed from the in situ developmental stage study as described in the Results section. GC chromatogram showing the product formation catalysed by BEAT (f), PAR (g) and MTS (h) enzymes extracted from flowers collected from different temperature conditions where product formation and substrate are marked, IS indicates internal standard used. Graphs represent the average values of three to five independent experimental setup where $\mathrm{SD}$ is represented in vertical lines. Data indicated with different alphabets differ significantly according to Tukey's HSD $(p<0.05)$.

Figure 7.Expression of scent related genes in J. auriculatum flowers grown under a range of fixed air temperatures successively in growth chambers. Plants were grown under four different temperature conditions viz. $20^{\circ} \mathrm{C}, 25^{\circ} \mathrm{C}, 30^{\circ} \mathrm{C}$ and $35^{\circ} \mathrm{C}$. Agarose gel images of amplified PCR product for $\Theta a \Pi A \Lambda, \Theta a B E A T, \Theta a \Pi A P$, $\Theta a M \Psi B, \Theta a \beta-\gamma \lambda v, \Theta a H M \Gamma \Sigma, \Theta a H M \Gamma P, \Theta a M T \Sigma$ transcripts in flowers collected from plants growing under different temperature conditions (a). Colour codes indicate the relative expression analysis of scent related genes by semi-quantitative RT-PCR where actin is used as the internal standard, lower intensity is indicated in green and higher intensity is indicated in red (b). RT-qPCR analyses of JaBEAT and JaMTStranscripts, the ultimate genes responsible for the biosynthesis of benzyl acetate and linalool, the major scent contributors in J. auriculatum (c). Values are represented as mean of three individual replicates where vertical lines indicate the SD. Data indicated with different alphabets differ significantly according to Tukey's HSD $(p<$ $0.05)$.

Figure 8. Changes in the relative contents of non-volatile metabolites in mature buds of $J$. auriculatum grown under a range of fixed air temperatures. Plants were grown under four different temperature conditions viz. $20^{\circ} \mathrm{C}, 25^{\circ} \mathrm{C}, 30^{\circ} \mathrm{C}$ and $35^{\circ} \mathrm{C}$. Mature buds growing under different temperature conditions were successively collected and freeze dried to obtain concentrated amounts of non-volatile metabolites. Colour code represents the relative abundance of individual compound as was calculated on the basis of ribitol, the internal standard (a). Light yellow and dark blue represent lowest and highest relative abundance of non-volatile metabolites. Values are represented as mean of five individual replicates. PCA score plot (b) and loading plot (c) of the non-volatile metabolite compounds collected from flowers of plants kept under different temperature conditions. PC1 and PC2 are the first two principal components. The score plot indicates the clear segregation of each temperature treated plants. The loading plot indicate the compounds responsible for the segregation of treatments.

Figure 9. A simplified overview of the pathways involved in biosynthesis of major volatile compounds in J. auriculatumflowers. The pathway genes and enzymes highlighted in blue are measured either in terms of the amount of active enzymes and/or gene expression levels from flowers at appropriate maturation stages (where maximum scent emission occurred) collected under varying air temperature regime. Colour code represents the abundance of floral volatiles emitted under different air temperature conditions where yellow and red represent lower and higher abundance, respectively. The formation of monoterpene volatiles take place in the plastid via the MEP pathway. The biosynthesis of phenylpropanoids/benzenoids and sesquiterpene volatiles occur in the cytoplasm via shikimate/chorismate and MVA pathways respectively. The dotted boundary around the phenylpropanoid/benzenoid biosynthetic pathway indicates that MYB transcription factor has a potential role in their regulation. Volatile compounds (marked as droplets) after glycosylation are transported to the vacuole for storage. Perhaps upon physiological necessity these stored glycosylated compounds are released as free volatiles by the aid of hydrolytic enzymes viz. $\beta$-glucosidase. Abbreviations: BEAT, acetyl-CoA:benzyl alcohol acetyltransferase; $\beta$-Glu, $\beta$-glucosidase; Ery4P, erythrose4-phospate; FPP, farnesyl pyrophosphate; GA-3P, glyceraldehyde-3-phosphate; GPP, geranyl pyrophos- 
phate; HMGR, hydroxymethylglutaryl-Coenzyme A reductase; HMGS, hydroxymethylglutaryl-Coenzyme A synthase; IPP, iso-pentenyl pyrophosphate; LOX, lipoxygenase; MEP, methylerythritol phosphate; MTS, monoterpene synthase; MVA, mevalonic acid; PAL, phenylalanine ammonia lyase; PAR, phenylacetaldehyde reductase; PEP, phosphoenolpyruvate; Phe, L phenylalanine; Pyr, pyruvate.

\section{Hosted file}

FIGURES for PCE new.docx available at https://authorea.com/users/336884/articles/462544floral-maturation-and-changing-air-temperatures-influence-scent-volatiles-biosynthesisand-emission-in-jasminum-auriculatum-vahl 